\title{
Sciendo
}

Administration, vol. 69, no. 1 (2021), pp. 143-171

doi: 10.2478/admin-2021-0010

\section{Programme of organisational capability reviews - Findings and learnings}

\author{
Gerry Cribbin 1 \\ Capability Review Team, Reform and Delivery Office, Department of \\ Public Expenditure and Reform, Ireland
}

\section{Introduction}

The five overarching themes covered in this article are as follows:

- Research model: purpose, background, governance, methodology and scope of the programme of organisational capability reviews;

- Leadership: direction by senior management, internal crossdivisional collaboration, cross-government working, EU engagement, and communications;

- Policymaking: capability and skills, business planning, synergies between related strategies, and available skills to undertake appraisals and evaluations;

- Delivery: efficacy of structures and processes to implement policies, strategies, programmes and schemes;

- Organisational capability: effectiveness of corporate functions such as HR, learning and development (L\&D), ICT and finance in supporting business units, and related activities around knowledge and data management.

1 This article was reviewed by Dave Hanley, who leads the Capability Review Team. 
This article draws together the principal findings from the six capability reviews undertaken to date, differentiating between areas of strength and matters requiring attention. ${ }^{2}$ It is intended that these findings will assist the development and implementation of reform initiatives, individually at organisational level and generally across the civil service.

As this article can only provide an overview of the findings from the reviews, readers may wish to refer to the published reports listed in Table 1.

Arising from Action 20 of the Civil Service Renewal Plan (Department of Public Expenditure and Reform, 2017), a programme of organisational capability reviews was put in place and, as part of which, six reviews were undertaken over the period June 2016 to June $2020^{3}$ (the programme, which had been paused due to the Covid-19 pandemic, is scheduled to resume shortly).

Table 1: Capability review reports

Organisation

Date of conclusion

of review

Department of Transport, Tourism and Sport

July 2017

(Capability Review Team, 2018b)

Courts Service (Capability Review Team, 2018a)

April 2018

Department of Business, Enterprise and Innovation

December 2018

(Capability Review Team, 2019)

Department of Culture, Heritage and the

July 2019

Gaeltacht (Capability Review Team, 2020)

Department of Housing, Planning and Local

December 2019

Government ${ }^{1}$

Department of Rural and Community Development ${ }^{1} \quad$ June 2020

1 The reports relating to these two departments have not yet been published. However, it is expected that they will become available soon, on finalisation by the departments of follow-up action plans and approval by government to publish.

${ }^{2}$ Some issues and findings on individual organisations may no longer be wholly or partially valid in that they may have been or are being addressed through follow-up action plans, or the matter concerned no longer falls within the remit of any of the six organisations reviewed, arising from departmental reconfigurations on the formation of the government in 2020 .

${ }^{3}$ The titles of the departments used in this article are those in use at the time of the reviews rather than their current states. 
The programme was overseen by a steering group drawn from the Civil Service Management Board (see Table 2).

Table 2: Steering group

\begin{tabular}{ll}
$\begin{array}{l}\text { Members of } \\
\text { sponsoring group }\end{array}$ & \multicolumn{1}{c}{ Department } \\
\hline Lucy Fallon-Byrne & $\begin{array}{l}\text { Assistant Secretary, Reform and Delivery Office, } \\
\text { Department of Public Expenditure and Reform }\end{array}$ \\
\hline Mark Griffin & $\begin{array}{l}\text { Secretary General, Department of Communications, } \\
\text { Climate Action and the Environment }\end{array}$ \\
\hline Seán Ó Foghlú & $\begin{array}{l}\text { Secretary General, Department of Education and } \\
\text { Skills }\end{array}$ \\
\hline Maurice Quinn & \\
\hline
\end{tabular}

${ }^{1}$ Maurice Quinn retired in June 2020 and was replaced on the group by Oonagh McPhillips, Secretary General, Department of Justice, in October 2020.

A review team based in the Reform and Delivery Office of the Department of Public Expenditure and Reform carried out the reviews. The team was supported by a nominated departmental liaison officer (DLO) from each organisation reviewed. The DLO provided logistical support, attended interviews and workshops, and assisted with drafting.

For each review, the team reported to a three-member External Review Panel, whose role was 'to review, validate, edit and finalise the report prepared by the team'.

The methodology was guided by a standards-based template, comprising four overarching filters: leadership, policymaking, delivery and organisational capability.

Terms of reference were developed and agreed at the outset of each review, prior to the commencement of which a management board usually partook in an away-day of self-reflection to assist the process in terms of focus, management and communications.

The evidential base for this article is derived predominantly from views expressed in staff workshops conducted internally within the organisation being reviewed and in one-to-one interviews with senior managers from both the organisation and external stakeholders, including any agencies. For the 6 reviews, a total of 381 engagements were undertaken, involving 1,248 participants, of whom 9 were ministers or ministers of state, 6 were presidents of courts, 48 were members of management boards and 148 were external stakeholders. 
Extensive use was also made of secondary research, principally core policy and corporate documents, along with the civil service staff engagement surveys conducted by the Central Statistics Office.

For each review report, the evidence is set out, findings are made and recommendations put forward, with the latter forming the basis for a follow-up action plan prepared by the organisation reviewed. On completion, the action plan and the review report are presented in composite form to government for approval to publish.

The capability reviews are concerned solely with an organisation's capability to deliver on its mission statement and do not involve any assessment of its policies, strategies, programmes or schemes in terms of their structures, outputs or impacts. Furthermore, the adequacy of staff complements are not examined, aside from those exceptional circumstances where the evidence clearly points to significant valueadded being forgone and/or major risk being borne due to insufficient numbers of appropriately skilled staff.

\section{Leadership}

Under this heading, consideration is given to leadership by senior management, the degree to which priorities are set and progressed, internal cross-divisional collaboration, cross-sector and crossgovernment working, and communications, both internal and external.

\section{Leadership by senior management}

There is high regard amongst stakeholders for the calibre, professionalism and competence of senior management, who face an ever-increasing multiplicity of demands. Balancing long-term planning against short-term demands is not an easy dilemma to resolve, as a core function of any department is to 'support the democratic process'.

The reviews suggest that departmental management boards are increasingly conscious of the need for diligence in ensuring that longterm strategic challenges should receive sufficient time and attention. To that end, a variety of protocols on conducting board meetings are in place involving, for example, specific schedules and time slots being ring-fenced for strategic discussions.

The reviews recommend, however, that boards should review quite regularly whether and in what way internal structures supporting their deliberations are in need of change, and that they should consider setting aside periodic times for self-reflection. 
Regarding departments with agencies under their aegis, there would appear to be an obvious benefit in an agency's senior management meeting formally face to face with their parent department's management board once or twice a year. Surprisingly, this practice is more the exception than the rule and, as a result, the reviews advocate that more formal planning and review arrangements should apply.

\section{Prioritisation}

It was recommended in some reviews that, insofar as practicable, the strategic orientation of an organisation might benefit from focusing on relatively few long-term strategic priorities rather than a large number comprised of both long- and short-term goals. In that respect, the Department of Business, Enterprise and Innovation (2017) adopts a novel approach in its Statement of Strategy 2018-2021. Notwithstanding its broad policy remit, the department encapsulates its strategic priorities into seven goals, underneath each of which is a series of outcomes.

\section{Internal cross-divisional collaboration}

Internal collaboration between business units faces two contradictory phenomena:

- Natural silos: On the one hand, the diversity of some organisations' business remits places limits on the extent to which collaboration between internal business divisions and constituent units would be either warranted or meaningful.

- Strive for common cause: Yet on the other hand, management and staff comprehend the value of strong internal collaboration, whether in terms of adding value to policy development, achieving efficiencies through process standardisation, or mitigating risks through shared learning.

Striking a workable balance between these impulses can be difficult, especially in regionally dispersed organisations. While collegiality amongst the members of management boards and collaboration between their business areas are reasonably strong, there is still considerable scope to promote the systemic sharing of expertise, knowledge and experience between internal business units.

In particular, the challenges faced by departments and other civil service bodies in effectively managing their significant capital 
programmes under Project Ireland 2040 (Department of Public Expenditure and Reform, 2018b) suggest that cross-divisional approaches and multidisciplinary teams may be needed to leverage scarce skills and ensure efficient delivery.

More generally, effective staff networks organised by grade, including at principal officer level, are more the exception than the norm. Such networks can be especially useful for improving internal communications, sharing knowledge and experience on common work challenges and, critically, assisting senior management with the successful delivery of challenging work programmes.

\section{Cross-sector and cross-government working}

A department's ability to influence policy development, at both national and EU levels, and to build coalitions of common cause across the government system is one hallmark of an effective and highperforming organisation. In that respect, the reviews produced a number of core findings:

- Cross-government engagement: Generally, departments play positive and active roles in cross-cutting forums, including cabinet committees and supporting senior officials' groups. High-quality engagement was particularly evident in the development of the National Development Plan, 2018-2027 (Department of Public Expenditure and Reform, 2018a) and the related National Planning Framework (NPF) (Department of Housing, Planning and Local Government, 2018a).

- Influencing whole-of-government agenda: Where a department has lead responsibility for a policy matter, or where there is a shared agenda with others, its ability to lead, influence and collaborate can often be a key strength. However, the capacity of departments to influence whole-of-government matters which are not core to their business but are relevant to it can be quite limited in certain circumstances. This is especially evident with the climate change agenda whereby skills gaps, staff churn and the retirement of specialist personnel have reduced the capacity of some organisations to contribute to deliberations as effectively as they should.

- Agreeing sectoral priorities: The reviews propose that in tandem with stronger cross-government collaboration, there is scope to deepen cooperation at a sectoral level. For instance, the review of the Courts Service found that the relationship with its parent department should be strengthened at a senior level, and that 
priorities should be set and monitored for the justice sector as a whole, including some for the Courts Service itself.

- Delivery by local government: Departments are increasingly reliant on the local government sector for the delivery of policies, programmes and schemes at local level. The reviews of both the Department of Housing, Planning and Local Government and the Department of Rural and Community Development found that the former is best placed to act as a catalyst for communicating across the government system on the implementation challenges faced by local authorities and on ensuring efficient and effective delivery by them.

- EU engagement: The reviews advocate that departments should reflect on whether and with whom they need to step up their interaction in the EU Parliament and Commission. In those respects, the reviews draw attention to the importance of engagement with parliamentary rapporteurs on legislative matters and with the Commission at the early stages of policy development so as to seek to influence its direction. Of note is that while departmental engagement in EU working groups is very good in some cases, there are also instances where departments struggle to give such groups the requisite attention. In particular, comprehensively servicing and supporting the biodiversity agenda has proved demanding, primarily as a result of tight staffing resources as well as the inherent challenges in giving effect to complex EU legislation.

- EU directives: On the transposition of EU directives, the general picture is that departments have performed quite well over recent years. However, natural heritage matters, especially on the protection of biodiversity, continue to be a challenge, due at times to the multiple stakeholders and multifaceted legislative obligations involved.

\section{Communications}

Civil service organisations are moving away from the traditional press office model which prioritised press releases targeted at reporters in newspapers, magazines, TV channels and radio stations and, instead, are establishing dedicated communications functions which are managed by professionally qualified personnel. This represents a significant cultural and organisational shift.

Some organisations have put in place a business partner model between the communications unit and line business units. In this way, 
it is intended that, over time, communications planning and support would become embedded at business unit level.

On external communications, there are examples of high-quality engagement with stakeholders and local communities when developing, explaining and implementing policies, programmes and schemes. Such engagement by the National Parks and Wildlife Service (NPWS), for example, is strengthening its ability to implement biodiversity policies in a sustainable manner and enhance awareness of their value amongst influencers and the public.

On internal communications, it is quite the norm now for senior management to go to considerable lengths to engage face to face with staff, including in geographically remote and dispersed locations, when developing and promoting major reform initiatives, and in preparing follow-up actions to the civil service staff engagement surveys (Central Statistics Office and Department of Public Expenditure and Reform, 2015, 2017, 2020).

Despite such good practice, three matters demand attention:

- Communicating impacts: Aligned to a separate finding in the reviews on the limited use of impact measurement, external communications are rarely focused on promoting a department's strategic role, particularly the long-term economic and social impacts of its policies and programmes.

- Use of social media: There are major variations in policies and practices regarding the use of social media. Policies on its use exist in some organisations and not in others, and practices vary widely, with both benefits and risks often poorly understood.

- Staff communications: Although management boards are usually quite diligent at debriefing principal officers on the deliberations and decisions at board level, they in turn do not always emulate that diligence in the form of follow-on updates to assistant principal officers and the wider body of staff.

\section{Policymaking}

This section deals primarily with policymaking, business planning, alignment between related strategies, and general capability to undertake appraisals and evaluations.

\section{New policies and strategies}

Most of the major strategic policy initiatives over the period from 2015 to 2020 provided inputs to, and are aligned with, two overarching 
national frameworks - the National Development Plan, 2018-2027 and the NPF - with the former providing the investment context by which the objectives of the latter will be pursued. These two national frameworks combine to form Project Ireland 2040.

In broad parallel with the formulation of these two frameworks, a range of new policies, strategies and programmes has been developed in such areas as enterprise development, transport infrastructure and housing. Some of the policy initiatives break new ground such as the National Social Enterprise Policy for Ireland 2019-2022 (Department of Rural and Community Development, 2019), which is the first policy statement of its kind in Ireland.

The reviews found that for complex and multifaceted areas of public policy, strategic change can be greatly assisted by the development of a well-researched policy framework. For example, the Framework Policy for Local and Community Development in Ireland (Department of the Environment, Community and Local Government, 2015) $)^{4}$ provided critical context and direction for the development of a subsequent suite of community-related strategies and programmes.

\section{Policymaking capability}

In recent years there has been a noticeable replenishment of the policy-oriented skills base, with the departments reviewed now having strong capability to develop high-quality policies. Within that context, exemplary stakeholder engagement practices and deep sector-based knowledge are notable strengths. Nonetheless, there are still some matters that are in need of attention:

- Policymaking competencies: Business units often seek input and support from specialist research units and/or individuals as they tend to have limited capacity and capability themselves to undertake high-quality research on new or emerging policy areas.

- Skills gaps: The reviews yielded much anecdotal evidence of capacity gaps relating especially to macroeconomic, appraisal and evaluation skills. Such evidence should now be tested in each organisation by quantitative measures for determining the scale of both current gaps and future needs.

\footnotetext{
${ }^{4}$ Prescribed local and community development functions were transferred from the Department of Housing, Planning and Local Government (previously Department of the Environment, Community and Local Government) to the Department of Rural and Community Development on its formation in 2018.
} 
- Agencies' expertise: There is a widespread view amongst agencies that departments could make greater use of their sectoral expertise and research capability, especially as inputs for assessing policy options.

A further issue on which departments might usefully reflect is whether they should opt for a centralised, distributed or hybrid model for the conduct of analysis and research. This matter was examined in some depth in the review of the Department of Business, Enterprise and Innovation.

For many years, the department relied on Forfás - the former independent state policy research and advisory agency - for much of its detailed enterprise policy analysis and research. In 2014 most of its functions and staff were integrated into the department and assigned to a newly created division called the Strategic Policy Division (SPD). The review found that, over the succeeding years, core capability around strategy and analysis became somewhat diluted. That arose primarily from staff churn, retirements and reassignments in the absence of a managed skills replacement programme.

In a detailed recommendation, the review advocated that the hybrid model, involving centralised analytical expertise in the SPD and dispersed analysts throughout policy divisions, is the most appropriate approach, as a critical mass of centralised competency is needed to nurture and grow analytical expertise on a continuous basis. In order to maximise their effectiveness, such centres of excellence should work in partnership with line policy areas on the basis of agreed work programmes and knowledge-sharing arrangements.

\section{Business planning}

The structures and practices for preparing statements of strategy have been much enhanced over recent years. Internal and external consultations on their development are strong, thereby generating considerable goodwill towards the process as a whole. A particularly novel and effective approach is used by Met Éireann whereby internal and external consultations are blended together and mediated through topic-specific task teams.

On the linkages between strategic planning and individual performance, the process works reasonably well as a framework within which the assignment and management of job roles are set. However, the uniformity of quality across business plans within departments is in need of attention. 


\section{Strategic alignment}

There are a variety of structures and mechanisms in place to ensure that there is cohesion between various national policy frameworks and departmental strategies and that they, in turn, guide regional and local authority based initiatives.

For example, each of the three regional spatial and economic strategies (RSES), which are prepared by the regional assemblies (Eastern \& Midland Regional Assembly, 2019; Northern \& Western Regional Assembly, 2019; Southern Regional Assembly, 2019), are required to be developed within the context of the NPF and be consistent with the objectives of Rebuilding Ireland (Department of Housing, Planning, Community and Local Government, 2016), and each local authority must frame its county or city development plan by reference to both the relevant RSES and the NPF. In those regards, the Office of the Planning Regulator independently assesses whether there is conformity and, if not, the minister can intervene.

\section{Appraisal capability}

The ex ante or forward-looking assessment of an investment proposal, commonly called an 'appraisal', constitutes a critical initial link in programme and project management.

The reviews concluded that optimal results are achieved when line policy units work in close partnership with a specialist appraisal function, arising from the fact that their deep policy and operational knowledge can be invaluable for providing guidance and challenging assumptions. However, not all departments with major capital programmes have such a function, thus necessitating a reliance on line business units to undertake appraisal work. In that respect, their capacity and capability varies greatly between organisations.

Notably, too, the reviews indicate that very few ex ante analyses of the strategic plans or investment programmes of departments and agencies are undertaken. The only such analysis undertaken in recent times by any of the six organisations reviewed was of the Strategic Framework for Investment in Land Transport (Department of Transport, Tourism and Sport, 2015) - an investment needs analysis of requirements to 2035 based on a 'steady state' assumption.

On appraisal capacity in the civil service generally, senior management in the Department of Public Expenditure and Reform and the departments reviewed are acutely aware that current capacity is inadequate. The response of some departments to date has predominantly taken two forms - the establishment of programme 
offices to oversee the delivery of sectoral programmes under Project Ireland 2040 and the undertaking of skills-needs assessments, including of appraisal capability.

The principal finding from the reviews is that appraisal capacity needs to be significantly bolstered if the capital plans and projects under Project Ireland 2040 are to be delivered efficiently, and the associated risks identified and mitigated effectively.

\section{Evaluation capability}

The ex post or retrospective assessment of an investment programme, project or scheme, commonly called an 'evaluation', can cast light on the dynamics of past performance, especially some features of best practice and any shortcomings, thereby helping in the future to strengthen decision-making and improve the design of similar initiatives.

There are examples of strategies and programmes having enablers for their future evaluation built into their design, with particular efforts being made to measure impacts. The 'Creative Ireland' programme is especially representative of best practice design whereby data to facilitate future evaluations are collected routinely as part of ongoing monitoring. Unfortunately, such practice runs against the general trend - for example:

- Major transport infrastructure projects: No ex post evaluations have been conducted or commissioned of some of the major national infrastructure projects over recent years - for example, the Luas, M50 upgrade and Dublin Port Tunnel projects.

- Enterprise-related evaluations: Up until 2015 most of the work of the SPD within the Department of Business, Enterprise and Innovation was on ex post evaluations relating to the work of either the department or its agencies. The review process confirmed, however, that the number of evaluations had reduced significantly between 2015 and 2018.

Notwithstanding the general underdeveloped state, there are some examples of a new approach:

- Culture, heritage and Gaeltacht projects and initiatives: Ex post evaluations feature as a regular business practice in these three broad policy areas. Notably, an emphasis is given to evaluation in their design and the collection of related data. In the opinion of 
stakeholders, the evaluations are produced to a high standard and include measurable actions which are followed up as part of the annual quality assurance process under the Public Spending Code (PSC) (Department of Public Expenditure and Reform, 2019).

- Preparation for future evaluation and impact measurement: The Action Plan 2018 to 2022 (Department of Culture, Heritage and Gaeltacht, 2018), which supports the delivery of the 20-Year Strategy for the Irish Language 2010 to 2030 (Department of Community, Equality and Gaeltacht Affairs, 2009), is strong on measurement. With a view to preparing the foundation for measuring impacts in terms of language proficiency and usage, the department has been working closely with the Central Statistics Office on devising and piloting a new set of questions for the next Census of Population questionnaire.

- Rural and community development evaluations: The Department of Rural and Community Development plans to adopt a programmatic approach to the evaluation of its schemes. In practice, this will mean that they will be evaluated in aggregated form under eight themes such as 'Programme for Rural Development' and 'Programme for Community Development'. Ultimately, the programmatic evaluations will follow the model set out in the PSC by reference to rationale, efficiency and effectiveness and, in that regard, the Economic and Social Research Institute (ESRI) is providing assistance.

Overall, the reviews made the following three core findings:

- Capacity underdeveloped: The capacity to undertake ex post evaluations is very limited in departments and is well below what it should be, given especially the scale and complexity of many programmes.

- Reviews not the norm: Post-project reviews are not standard business practice and need to become embedded as a business norm in order to apply lessons learned and determine realised benefits against expected gains.

- Impacts need attention: Although there are examples of good practice and planning regarding the measurement of impacts, insufficient priority and effort are devoted to developing structures and processes for such work, thereby making ex post evaluations much more difficult to conduct than they ought to be. It would be especially useful therefore to determine at the outset of a new initiative those indicators most appropriate for measuring impacts 
and to put systems in place for the routine collection of constituent data in order to facilitate high-quality evaluations into the future.

\section{Delivery}

This section examines the effectiveness of structures and processes to implement policies and strategies, major national programmes and the wide variety of schemes administered by some departments.

\section{Delivery of policies and strategies}

A critical challenge when developing a new policy or strategy is to work through how long delivery will take and what needs to be done to transform it into an actionable agenda. In those respects, the reviews reached two core conclusions:

- Implementation in design: There are some strong examples whereby outputs, timelines, senior responsible owners and implementation mechanisms are incorporated into the design of new policies and strategies. For instance, the River Basin Management Plan for Ireland, 2018-2021 (Department of Housing, Planning and Local Government, 2018b), which complements the Water Services Policy Statement (Department of Housing, Planning and Local Government, 2018c), is particularly strong on implementation mechanisms and provides for a broad range of specific sector- and community-based actions which require multidisciplinary and cross-agency approaches. However, the reviews also uncovered examples whereby delivery is not given sufficient attention in the design of strategies. Relatively common shortcomings include underdeveloped performance targets and a lack of clarity regarding the lead owners for some actions, especially those spanning a number of organisations and internal divisions.

- Local-level guidance: For strategies that rely heavily on communitybased groups for delivery, local-level guidance and support can be especially valuable. A pertinent example is the advisory service provided by Údarás na Gaeltachta to community groups for the twenty-six local language plans in Gaeltacht areas to support delivery of the 20-Year Strategy for the Irish Language, 2010-2030. Overall though, there is considerable scope for the further development of standardised guidance for delivery purposes.

The thrust of the evidence is that departments are increasingly conscious of the need for new policies and strategies to have 
implementation targets and delivery mechanisms built into their design. However, greater account generally needs to be given to the factors, resources and timelines impacting on the delivery of policies and strategies at the time of their development.

\section{Delivery of major infrastructure programmes}

Some organisations have responsibility for delivering major national programmes, especially large-scale capital plans under the $€ 116$ billion Project Ireland 2040 investment strategy.

Regarding delivery strengths, the reviews made three core findings:

- Delivery model: The centralised overarching structures and processes to provide support and oversee delivery of the various investment programmes under Project Ireland 2040 are well designed and led.

- Programme and project management capacity: Some departments have taken the critical first steps towards ensuring that they will have the necessary structures, staff and skills to deliver on their respective programmes. As already noted, those first steps include assessments of future skills needs and the establishment of programme offices.

- Collaboration with delivery entities: Some strong partnerships between national and local-level delivery entities are being developed or strengthened to foster effective implementation. For example, delivery of the 'Creative Communities' initiative, as part of the Creative Ireland programme, involves considerable collaboration between the relevant lead departments and a culture and creativity team in each of the thirty-one local authorities to foster collaboration and new initiatives. Each team comprises cross-sectoral expertise from the arts, heritage, libraries, enterprise and communities. Through such means, each local authority is implementing a five-year Culture and Creativity Strategy, 2017-2022.

A particularly positive observation is that management boards recognise Project Ireland 2040 as offering a major step change in capital investment across a broad range of sectors and activities. Driven by that recognition, there is a strong determination on their parts to achieve successful and sustainable outcomes.

Regarding delivery challenges, a number of conclusions were reached: 
- Structural delivery challenge: Departments face considerable challenges in seeking to deliver efficiently and effectively on the ambition of the various programmes under Project Ireland 2040. Those challenges relate fundamentally to the development of well-designed and appropriately resourced programme and project management structures and systems at a departmental level.

- Delivery master plan: Well-researched assessments of phased delivery are critical for successful outcomes. Such assessments in individual organisations would need to differentiate between types of projects, schemes and programmes and include estimates of investment needs, likely sequencing of delivery, and indicative timetables for commencement and completion.

- Skills-needs assessments: A notable feature of Project Ireland 2040 is that much of the delivery will be back-ended over the life of the investment strategy, with the early stages being devoted primarily to appraisal and planning activities. Thus, a delivery master plan would need to include a comprehensive skills-needs analysis differentiating between short- and medium-term requirements as projects mature through the project life cycle.

\section{Delivery of other programmes and schemes}

Apart from those investment plans set within the context of Project Ireland 2040, some of the six organisations reviewed have responsibility for implementing a variety of other national programmes such as the 'Decade of Centenaries 1913 to 1923' programme, Creative Ireland, the Social Inclusion Community Activation Programme and LEADER. The reviews found that implementation, although involving a variety of delivery models, is notably strong with regard to stakeholder engagement and, in the cases of the Creative Ireland and LEADER programmes, to linkages between financial inputs and creative/developmental outputs at aggregate and local levels (see Table 3).

\section{Customer service}

The principal finding is that call monitoring, customer surveys and focus groups to assess service delivery against customer expectations are not commonplace except for some public-facing transactional services such as the Shannon-based Driver and Vehicle Computer Services Division. On user groups specifically, the Courts Service is quite exceptional in having such groups in place for testing and 


\section{Table 3: Example of effective delivery in a challenging environment}

The suite of largely stand-alone schemes administered by the Department of Rural and Community Development provides a good example of how implementation in a complex environment can be done successfully.

The core finding is that, despite the involvement of a myriad of state agencies, local authorities and community-based bodies, delivery is a strong point of that department. The extended delivery model, though cumbersome, performs in a reasonably effective way, despite a fragmented ICT state apart from those schemes administered by Pobal. The reason lies in three strengths:

- Relationships with local government: The department's relationships with the local government sector, which are critical for delivery purposes, are managed very well, at both senior management and business unit levels.

- Service provided by Pobal: Managers and staff rate very highly Pobal's quality of service - the supporting ICT systems are state-of-the-art, the data infrastructure is strong, and regular reports are provided on schemes by reference to inputs, outputs, target groups and costs.

- On-the-ground engagement: Senior managers from the department make major efforts to get on-the-ground exposure regarding the challenges faced in actual delivery. As part of those efforts, strong relationships have been forged with local authorities, entities under their aegis and community organisations.

refining service offerings. Generally though, service quality is not tested to the extent that it should be and, as a consequence, potential opportunities to improve service and promulgate good practice are forgone.

\section{Innovation and continuous improvement}

The findings from the capability reviews synchronise closely with those from the 2017 Civil Service Staff Engagement Survey, which suggests strongly that innovation is in need of attention. Although there is ample evidence of innovation in policymaking, the situation is more diffuse regarding operational activities.

Of particular note is the need for organisations to give priority and attention to standardising processes, procedures and protocols for the administration of same and similar tasks, and their subsequent dissemination amongst staff. 


\section{Governance}

The governance by departments of agencies under their aegis is proportionate and well managed, with management and staff having a deep knowledge of the business of individual agencies and the environments within which they operate. However, that generally positive finding is tempered by a common complaint from agencies (particularly the commercial companies) that parent departments can be overly concerned with micro-managing them and that, rather than focus on the big strategic issues, they devote far too much time and scarce resources on probing matters that are more appropriate to an agency's management and board of directors.

Governance models typically include all the features of best practice such as oversight agreements, performance delivery agreements, face-to-face review meetings and responsive liaison arrangements.

Although the reviews do not recommend in favour of any particular governance model, they nonetheless propose that where a department has many and varied agencies, consideration should be given to establishing a centralised governance function if not already in place. Such a function would act as a centre of advice and assistance to line divisions, and help ensure a cohesive application of policy, including on appointments to boards.

\section{Risk management}

Although risk is managed reasonably well, a number of concerns still exist:

- Risks on risk register: Some organisations include far too many risks on the departmental risk register, thus making it difficult to make discriminating assessments regarding importance, probability and impact. Although the reviews did not produce any findings on the appropriateness of risks identified on registers, it was somewhat surprising that some strategic risks tend not to feature, such as upcoming large-scale retirements, the impending loss of specialist staff and the ongoing dependence on certain ICT applications for which there is a dwindling support base.

- Risk mitigation: The follow-up mitigating actions vary in quality and effectiveness between organisations and internal business areas, thus pointing to a need for stronger organisation-wide standards and guidance to be set, communicated and implemented. 
- Risk awareness: Awareness of risk amongst staff varies significantly and remains considerably underdeveloped as a business planning instrument.

- Legal capacity: The legal support services available within departments are often very limited, thereby giving rise to avoidable risk. In particular, some departments would appear to need specialist environmental legal support to develop standardised guidance on interpreting and applying regulations under EU directives.

\section{Organisational capability}

This section deals with organisational identity, the effectiveness of HR functions, strategic HR planning, and staff management and development, as well as capability in other corporate functions such as ICT, and knowledge and data management.

\section{Organisational identity}

A department can have multiple missions and affiliations, with the sense of affinity felt by staff being anchored first and foremost on the business area in which they work or the policy area they serve. For example, staff working in the NPWS tend to identify themselves with that entity rather than their department as a corporate body, thereby presenting senior management with challenges around organisational cohesion.

The review of the Department of Culture, Heritage and the Gaeltacht, which underwent seven reconfigurations of functions between 1993 and 2017, provides some pointers on how such cohesion might be achieved. In particular, the management board worked diligently at developing a holistic departmental identity and encouraging affiliation to the department's mission statement. To those ends, senior management engaged regularly and formally with staff on their concerns, and provided demonstrable reassurance on their resolve to addressing them.

\section{HR functions}

Civil service organisations have transitioned much of their transactional HR activity to the shared services centre, PeoplePoint. In parallel, a number of reforms have been introduced over the past five years or so which are having a significant bearing on service delivery: 
- Professionalisation: The six reviews indicate that, increasingly, HR units are being led by professionally qualified managers who have considerable external experience.

- Business partnering: The HR Business Partner model, which is intended to work alongside strategic workforce planning, is now commonplace and is designed to provide the critical link and form the core relationship between the HR unit and business units and their staff. Generally, the model appears to be bedding in quite well.

The reviews concluded that the professionalisation and restructuring of HR functions, although taking an inordinately long time to implement, are nonetheless preparing the ground for stronger orientation on strategic matters into the future.

\section{Strategic HR planning}

Management boards and HR units are increasingly challenged to pursue a more strategically focused agenda than in the past and, in that respect, the reviews produced three core findings:

- Management boards - strategic deliberations: Boards tend not to devote sufficient time to considering medium- to long-term strategic HR challenges; for example, there is a tendency to focus disproportionately on relatively micro matters that properly belong to bilateral engagement between a HR unit and assistant secretaries and/or principal officers.

- HR units - strategic orientation: Typically HR units are producing more policy-focused HR papers than in the past for deliberation by management boards on such issues as strategic workforce planning, sick leave trends and Performance Management and Development System (PMDS) statistics.

- HR strategies: A notably positive development is that all of the organisations reviewed now have HR strategies in place, with an increasing emphasis being given to analytics for predictive purposes and the development of targeted interventions in the areas of workforce planning and staff well-being.

Overall, there are indications that the increased professionalisation of HR units is generating a more strategic HR focus at management board level and, in that respect, the People Strategy for the Civil Service, 2017-2020 (Department of Public Expenditure and Reform, 2016) has provided critical context and been a key driver. 


\section{Strategic workforce planning}

Some organisations such as the Courts Service have quite welldeveloped workforce plans whereas others are in train. More generally, strategic workforce planning is still in the early stages of development, with some organisations having raised insufficient guidance on best practice as an issue. Although receiving increasing attention at management board level, the linkages between business priorities and staff allocations still remain underdeveloped.

In addition, there is a lack of understanding among the generality of civil servants on what strategic workforce planning actually means and involves, with many of them perceiving the exercise as little more than a process for allocating resources and filling vacancies. Thus, it is important that awareness at business unit level is fostered regarding the aims and requirements involved.

\section{Retirement cliff}

A matter of special relevance to strategic workforce planning is the retirement cliff facing a number of the organisations reviewed - for example, 35 per cent of staff in the Courts Service are over fifty-five years of age, many of them occupying senior specialist positions. ${ }^{5}$

Amongst the principal features and effects are the loss of corporate memory, a disruption to business continuity and an increased business risk where retirements are likely to be clustered by specific skills in certain locations, such as regionally based ecologists in the NPWS.

Although typically a management board is attuned to the potential impacts of a looming retirement cliff on the organisation's capacity and capability, it tends not to prioritise the development of a comprehensive response.

\section{People management}

Performance management is aimed at providing managers and jobholders with a tool to help them manage and improve performance. Its key elements include goal setting, competency selection, learning targets and performance reviews. The formal recording of such information is done through the PMDS.

The evidence on the process is notable for the consistency of opinion in the following respects:

5 The quoted statistics relate to a point in time corresponding closely to the conclusion of each individual review. 
- Performance management - leadership: More proactive leadership is needed to leverage PMDS as a means of effectively managing performance, supported by focused leadership training.

- Performance management - application: The management of staff through the PMDS process is not done in a consistent manner. There are variations within and between organisations regarding the regularity of review meetings, and there is a widespread perception that senior management tends to focus excessively on compliance rates and insufficiently on the quality of performance management. For such reasons, the reviews suggest that the HR Business Partner model might usefully include a specific role for monitoring the quality of performance management in each business unit, including the regularity of meetings.

- Performance management - underperformance: The processes and procedures for managing underperformance are highly complex, onerous and time-consuming, and there is considerable scope for simplification and standardisation. Some organisations are now upskilling managers to deal effectively with underperformance and are putting in place some positive mitigating actions. For example, a feature of one of the modules of a coaching programme run by the Courts Service is aimed specifically at upskilling managers from higher executive officer upwards in tackling underperformance and assisting them to initiate the necessary 'challenging conversations' in that regard.

\section{People development}

Each of the six organisations reviewed has in place an L\&D strategy which includes a comprehensive programme of training courses administered through the civil service's OneLearning ${ }^{6}$ shared services platform.

More generally, L\&D units have built up good working relationships with business units and staff, with interviewees being especially laudatory of the significant improvement in service responsiveness and training provision over recent years.

The reviews revealed a number of other notable features and practices, including the following:

- Linkages between performance management and training: Most training needs are identified through PMDS.

${ }^{6}$ Civil service's shared service for L\&D, which has been operational since late 2019. 
- Management training: Challenges arise in some organisations from the relative inexperience of principal officers and assistant principals. For example, in the Department of Housing, Planning and Local Government, twenty-nine principal officers (45 per cent of the total) have only three or less years' tenure in their current grade. A number of senior managers believe that there is a need for targeted interventions to deal with such challenges, primarily by way of staff development initiatives, coaching and mentoring.

- Evaluating the impacts of L\&D: Measuring and evaluating the impacts of investments in L\&D is rarely done, even though it would provide organisations with the evidence base to refine offerings as necessary, change course content, and develop analytics for input into future people development strategies. Of the six organisations reviewed, the most developed model exists in the Courts Service, which uses the Kirkpatrick Model to measure the effectiveness of interventions.

\section{Capability in ICT}

From a new development perspective, there are examples of highquality product: (a) the implementation of Build-to-Share applications, which are hugely beneficial for administering day-to-day work such as processing freedom of information requests; and (b) bespoke solutions like the LEADER Grants Management System, which has end-to-end functionality that takes account of EU-based obligations and accreditations.

Notwithstanding such positive initiatives, the overall ICT state is in need of much attention, as demonstrated by broad sets of findings which principally encapsulate the following concerns:

- Underdeveloped business tool: ICT as a management and business tool remains significantly underdeveloped. In some organisations the current state is characterised by paper-based processes, standalone databases and poor interoperability between related applications - a legacy in part of piecemeal planning and uneven strategy.

- Non-interoperable systems: There are examples whereby systems, even though set logically within a process chain, operate in an independent manner. For example, charge sheets from An Garda Síochána are furnished to the Courts Service in paper form and often at short notice - staff have to type up the details onto the 
Criminal Case Tracking System, which performs a number of courts-related functions such as the generation of warrants and the production of court lists.

- Strategic reorientation: In order to strengthen strategic ICT orientation and capability, some of the reviews have recommended the establishment of a dedicated strategic unit within the ICT function that would conceptualise and map out a transformational ICT strategy and programme.

- Business Support Unit: Organisations might usefully consider emulating the initiative of the Department of Housing, Planning and Local Government which has established a Business Support Unit as a subset of its ICT function to work with business units on ways to improve processes and procedures as a precursor to developing new business solutions.

\section{Capability in finance}

The six organisations reviewed have their own finance functions, which are responsible for overseeing and reporting on current and capital expenditure, especially out-turns relative to profiles. The management of finance is an area of particular strength. Invariably, the finance units are professional, high-performing, customer-focused operations that command widespread respect and support.

\section{Capability in knowledge management}

The general situation is improving with regard to the management of records. The incremental roll-out of the electronic records management system eDocs across the civil service constitutes a significant positive step in standardising protocols and practices around the storage and archiving of electronic-based records.

More generally, there is considerable scope for improvement in the area of succession planning. Standardised approaches for harnessing corporate knowledge, especially of specialist staff facing into retirement, tend not to exist and, as a result, a retiree can leave behind a major knowledge void.

In a related vein, there is an inconsistent approach to developing and maintaining job manuals. Operational areas are usually quite strong on documented procedures, although there is scope in some instances for augmentation through process mapping. However, documentation becomes less commonplace as work gravitates towards policymaking. 


\section{Capability in data management}

Although effective for planning and delivery purposes, data management remains considerably underdeveloped as a business instrument, despite some improvements over recent times.

The shortcomings are numerous and include the following:

- Data policy and strategy: Only one of the six organisations reviewed had a data management policy in place when the reviews were being conducted.

- Data integration: In each of the six organisations, there are significant numbers of stand-alone applications, databases and data sets where the linkages between sets with shared attributes are either poorly developed or non-existent.

- Data analysis and presentation: As a consequence of the heavily fragmented data environment and the use of systems that are not amenable to statistical interrogation, comparative analysis is often difficult and the production of statistical reports is excessively labour intensive.

- Combination of Geographic Information System (GIS) ${ }^{7}$ and unique identifiers: The deployment of GIS capability for the interrogation and presentation of data is much underdeveloped, even though valuable benefits could be derived from the combined use of GIS and unique identifiers. For example, the review of the Department of Rural and Community Development found that such a combination could be very helpful for assessing the impacts of schemes on various socio-economic groups, and for identifying the extent of overlaps between schemes.

Despite the shortcomings, there are examples of good practice, as well as evidence of a generally improving situation:

- Data management skills: Four of the six organisations reviewed have some dedicated unit or person with the requisite statistical and analytical skills, although their numbers tend to be very small usually just one to three people.

- Local authorities' housing data: A new ICT system is being developed which ultimately will replace that currently in use for managing the housing data provided to the Department of

${ }^{7}$ GIS is a computer system for capturing, storing, checking and displaying data related to positions on Earth's surface. 
Housing, Planning and Local Government by the thirty-one local authorities. The objective is to bring about impactful improvements and changes in the management, storage and reporting of such data.

- Research partnerships with the ESRI: Both the Department of Housing, Planning and Local Government and the Department of Rural and Community Development have research partnership agreements with the ESRI.

- Unique identifiers as an aid to analysis: The reviews uncovered a number of examples which demonstrate the value and potential of unique identifiers - PPSNs (Personal Public Service Numbers) and Eircodes - for assisting with developing policy, assessing options and delivering services. For instance, they are used by the shared service operated by Limerick City and County Council to match recipient data under the Housing Assistance Payment scheme with property data in a harmonised manner across all local authorities.

The overriding message from the reviews, however, is that the necessary data infrastructure to facilitate planning, ongoing monitoring and eventual feeds into evaluation tends to be either underdeveloped or not in place. Categorisation practices, data management processes, statistical supports and ICT systems are in need of special attention. Overall, data policy and management are not treated as a priority in the organisations reviewed, and that needs to change.

\section{Conclusion}

The capability review programme has been especially useful in helping civil service organisations to discern their strengths as well as those matters in need of attention and action. The standards-based methodology, which guides the process, facilitates deep investigation and analysis of an organisation's business model by reference to leadership, policymaking, delivery and organisational capability, and their constituent attributes.

The programme has been valuable, too, in pointing towards solutions by means of recommendations which are peer reviewed by experienced and senior personnel drawn interchangeably from the public service, academia and consultancy practices. Those recommendations form the bedrock of the action plans prepared by 
the organisations reviewed, which have all reported that the experience was positive and beneficial.

A particular feature of the six reviews to date has been the depth and honesty of engagement by management, staff and stakeholders, which has generated respect for the process and given the findings and recommendations a strong evidence-based authority.

Looking across the reviews, the evidence suggests that the following matters are in need of special attention on the part of the civil service generally:

- Deliberations by management boards: Undertaking periodic selfreflection exercises on strategic matters relating to the organisation and the sector(s) for which it has responsibility, and reviewing regularly whether and in what way internal structures supporting a board's deliberations are in need of change.

- Appraisal and evaluation capacity: Significantly bolstering appraisal capacity to secure efficient delivery under Project Ireland 2040 , building capacity to undertake ex post evaluations, which is well below requirements, and giving an invigorated impetus to the measurement of impacts.

- Research model: Deciding on the most appropriate model for the conduct of analysis and research. A detailed assessment in one of the reviews found that a critical mass of centralised competency is needed to nurture and grow analytical expertise on a continuous basis.

- Workforce planning: Moving workforce planning onto the next stage of maturity whereby the linkages between business priorities and staff allocations are strengthened, and awareness is fostered at business unit level regarding the aims and requirements of the process.

- Strategic ICT: Significantly developing strategic ICT capability so as to maximise efficiency and effectiveness through, in particular, systemic interoperability between related business activities, underpinned by strong process standardisation.

- Data management: Scoping and developing the end-to-end data infrastructure needed to facilitate efficient and effective planning, monitoring, measurement and evaluation. 


\section{References}

Capability Review Team. (2018a). Organisational capability review - Courts Service. Dublin: Courts Service.

Capability Review Team. (2018b). Organisational capability review Department of Transport, Tourism and Sport. Dublin: Department of Transport, Tourism and Sport.

Capability Review Team. (2019). Organisational capability review - Department of Business, Enterprise and Innovation. Dublin: Department of Business, Enterprise and Innovation.

Capability Review Team. (2020). Organisational capability review - Department of Culture, Heritage and the Gaeltacht. Dublin: Department of Culture, Heritage and the Gaeltacht.

Central Statistics Office and Department of Public Expenditure and Reform. (2015). Civil service staff engagement survey. Dublin: Government of Ireland.

Central Statistics Office and Department of Public Expenditure and Reform. (2017). Civil service staff engagement survey. Dublin: Government of Ireland.

Central Statistics Office and Department of Public Expenditure and Reform. (2020). Civil service staff engagement survey. Dublin: Government of Ireland.

Department of Business, Enterprise and Innovation. (2017). Statement of strategy 2018-2021. Dublin: Department of Business, Enterprise and Innovation.

Department of Community, Equality and Gaeltacht Affairs. (2009). 20-year strategy for the Irish language 2010 to 2030. Dublin: Department of Community, Equality and Gaeltacht Affairs.

Department of Culture, Heritage and Gaeltacht. (2018). Action plan 2018 to 2022 - 20-year strategy for the Irish language, 2010-2030. Dublin: Department of Culture, Heritage and Gaeltacht.

Department of Housing, Planning and Local Government. (2018a). National planning framework. Dublin: Department of Housing, Planning and Local Government.

Department of Housing, Planning and Local Government. (2018b). River basin management plan for Ireland, 2018-2021. Dublin: Department of Housing, Planning and Local Government.

Department of Housing, Planning and Local Government. (2018c). Water services policy statement. Dublin: Department of Housing, Planning and Local Government

Department of Housing, Planning, Community and Local Government. (2016). Rebuilding Ireland. Dublin: Department of Housing, Planning, Community and Local Government.

Department of Public Expenditure and Reform. (2016). People strategy for the civil service, 2017-2020. Dublin: Department of Public Expenditure and Reform. 
Department of Public Expenditure and Reform. (2017). Civil service renewal plan. Dublin: Department of Public Expenditure and Reform.

Department of Public Expenditure and Reform. (2018a). National development plan, 2018-2027. Dublin: Department of Public Expenditure and Reform.

Department of Public Expenditure and Reform. (2018b). Project Ireland 2040. Dublin: Department of Public Expenditure and Reform.

Department of Public Expenditure and Reform. (2019). Public spending code. Dublin: Department of Public Expenditure and Reform.

Department of Rural and Community Development. (2019). National social enterprise policy for Ireland 2019-2022. Dublin: Department of Rural and Community Development.

Department of the Environment, Community and Local Government. (2015). Framework policy for local and community development in Ireland. Dublin: Department of the Environment, Community and Local Government.

Department of Transport, Tourism and Sport. (2015). Strategic framework for investment in land transport. Dublin: Department of Transport, Tourism and Sport.

Eastern \& Midland Regional Assembly. (2019). Regional spatial and economic strategy for the Eastern and Midland Region. Dublin: Eastern \& Midland Regional Assembly.

Northern \& Western Regional Assembly. (2019). Regional spatial and economic strategy, 2020-2032. Ballaghaderreen: Northern \& Western Regional Assembly.

Southern Regional Assembly. (2019). Regional spatial and economic strategy for the Southern Region. Waterford: Southern Regional Assembly. 